\title{
Critical Success Factors of eLearning in Distance Education Program in a Developing Country
}

\author{
Nusrat Zahan Mou', Salah Uddin Rajib ${ }^{2, *}$ \\ ${ }^{1}$ Open School, Bangladesh Open University, Gazipur-1705, Dhaka, Bangladesh \\ ${ }^{2}$ Department of Accounting and Information Systems, Jahangirnagar University, Dhaka-1342, Bangladesh \\ *Corresponding author: rajibais@juniv.edu
}

Received January 03, 2019; Revised February 09, 2019; Accepted March 29, 2019

\begin{abstract}
This paper aims to identify the critical success factors (CSFs) of eLearning in distance education/learning program in a developing country, Bangladesh. Distance education program is accredited in overcoming a number of barriers in education, especially time constraint and geographical location. eLearning is often used as a means of distance education program. In previous researches a number of bottleneck are identified in distance education as well as in eLearning. In Bangladesh, Bangladesh Open University (BOU) is solely authorized to conduct the distance education. The aim of $\mathrm{BOU}$ is to distribute the knowledge in remote areas and to the community of unprivileged. BOU has taken the eLearning as the premise of strengthening the distance education program. This study aims to identify the critical success factors (CSFs) that are necessary to ensure the effective distance education through eLearning on the priority basis. As Fuzzy Analytical Hierarchy Process (FAHP) is recognized extensively for identifying the actions required on priority basis, FAHP is used to conduct the study.
\end{abstract}

Keywords: Education Management, Distance Education, eLearning, Fuzzy Analytical Hierarchy Process (FAHP), Critical Success Factors (CSFs), Bangladesh

Cite This Article: Nusrat Zahan Mou, and Salah Uddin Rajib, "Critical Success Factors of eLearning in Distance Education Program in a Developing Country.” American Journal of Educational Research, vol. 7, no. 3 (2019): 299-303. doi: 10.12691/education-7-3-16.

\section{Introduction}

The history of distance education is rooted in Isaac Pitman's shorthand lessons when he offered shorthand lessons through the mail in 1840 in England. Later the distance education systems got institutionalized through the university. The British Open University plays the main role in this regard [1]. The history of education experienced a number of technologies as means of communication. The information technologies, audio visual including radio, television, internet, intranet and others have enriched the means of communication. The communication paradigm of education in distance education is not an exception. ELearning is seen as a means of communication in distance education frequently [2,3].

Bangladesh Open University (BOU) was established in 1992 which aims to provide distance education in Bangladesh. It is one of the top universities in the world regarding the enrolment of the students. The mission of the BOU is identical with the core of open and distance education which is providing access to more people, teaching faster, better, and more affordable without any age restriction. Though BOU has several schools, its Open School is playing the key role of the university. In Bangladesh, the Bangladesh Open University (BOU) has taken eLearning as a central platform for distance education $[4,5]$.
ELearning is accredited to overcome a number of barriers. More than 50 countries through 1000 institutions are using ELearning as a mechanism to spread out the educations [6]. The implementation of eLearning is challenging. Both in the developed and in developing countries a number of challenges are identified. Problems of dropping out, lack of interaction with the students, infrastructural problems, content of course and others are identified as the challenges in eLearning. Therefore, this paper aims to investigate the factors that are critically important for adoption of eLearning in the distance education of BOU in Bangladesh, a developing country.

The aim of the paper is four folded. After discussing the previous researches in literature review a model has been selected in section one. In section two, research method is disclosed. In section three, a discussion and analysis on the critical success factors (CSFs) of implementing the eLearning in Bangladesh are presented. Finally, a conclusion is drawn.

\section{Literature Review}

In prior research definition, effectiveness and implementation mechanisms of eLearning as well as distance education are discussed. Although in some universities eLearning and distance learning are used interchangeably, researchers notice the differences between them [7]. 
Probably the history of distance education is much older than eLearning and online learning which stayed back almost two century, rooted in 1840 in England [1]. With the time, mechanisms of distance education program have enriched through the concept and the advancement of technology. While once the distance education used the mechanisms like postal service, nowadays eLearning is adopting in many ways. Prior researches argued that distance education can use emerging media to distribute the knowledge [8]. Consisting with that it can be said that distance education can use both the printing and electronic media e.g., eLearning, online learning and others can be used [7]. It is seen that eLearning is studied widely as a means of distance education in prior research [2,3]. In previous studies website, internet, intranet, audio and video tape, satellite broadcasting, interactive television program are seen as means of eLearning [7,9].

An increasing number of scholarly works are devoted to the successful implementation of eLearning (e.g., as in $[6,10,11,12,13])$. Prior researchers have identified the critical success factors (CSFs) of eLearning from the perspective of organizational issues, students' perceptions, national economical state and others. McPherson and Baptista Nunes studied the organizational CSFs for eLearning in higher education. They identified 66 CSFs under four clusters - Leadership, structural and cultural issues (31), design issues (12), technological issues (7) and delivery issues (6). Selim conducts a study on students' perceptions regarding the CSFs of eLearning. Economical state of the country has received concentration of the researchers to study the CSFs of eLearning (e.g., as in $[6,14,15,16])$. Andersson and Grönlund have suggested four factors with sub-factors for studying the CSFs of adaptation of eLearning in developing countries. They are - individual challenges (student and teacher), course challenges (course design and support provided), contextual challenges (organizational and societal/cultural) and technological challenges. By considering the technology adoption criteria Bhuasiri et al. develop and investigate the CSFs in a developing country. To identify the factors they use Analytical Hierarchy Process (AHP) which is presented in Figure 1.

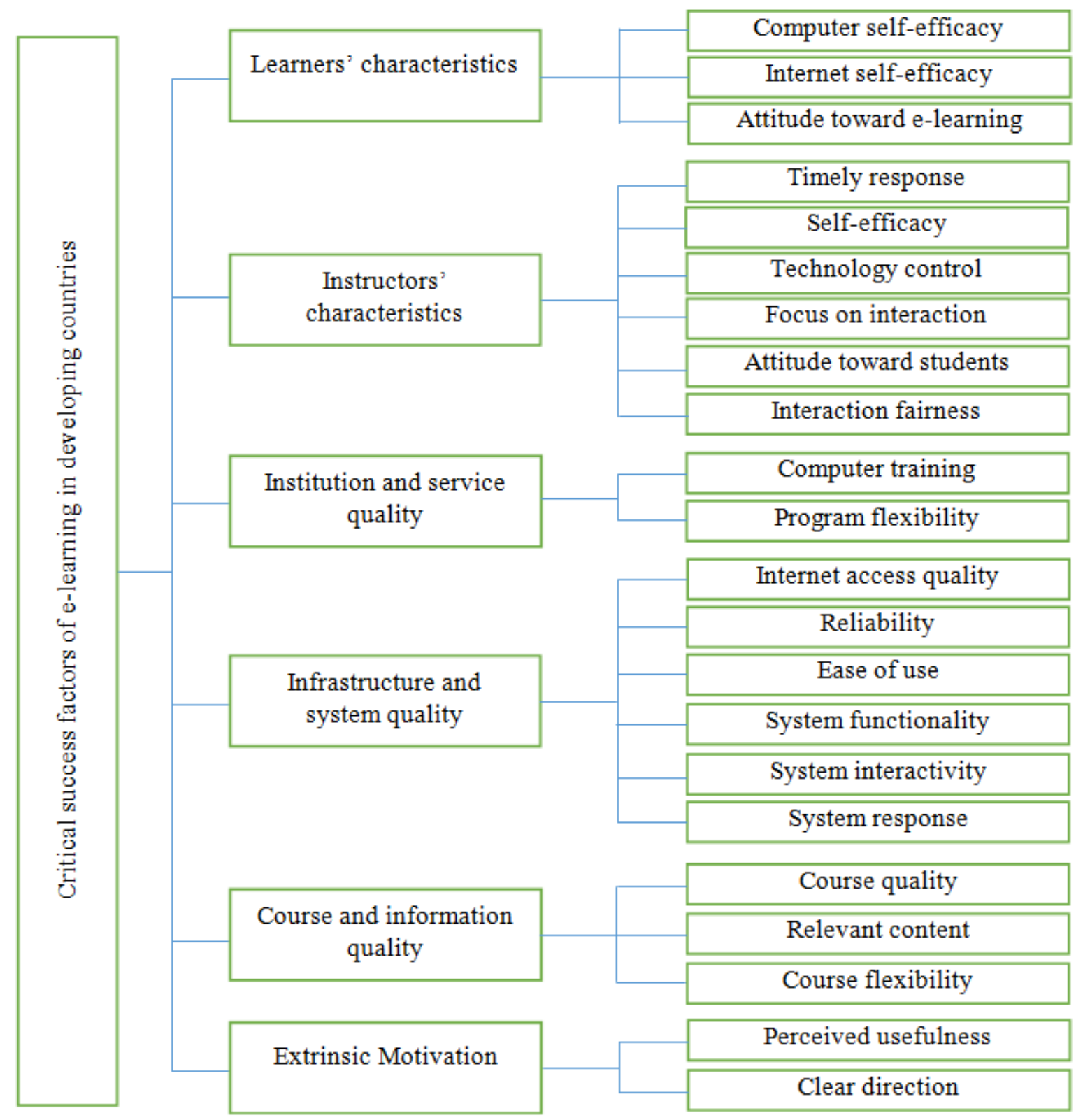

Figure 1. Critical success factors of eLearning (Source: Bhuasiri et al., 2012) 


\section{Research Methods}

This study has used the model offered by Bhuasiri et al. (2012) considering the surroundings. As Bangladesh is a developing country, it seems that the model offered by Bhuasiri et al. will well match with the avenue of the study.

To find out the CSFs, methodology of prior research is adopted [17]. To find out the CSFs, application of Fuzzy Analytical Hierarchy Process (FAHP) is highly accredited. As in Bangladesh - a developing country, only BOU is authorized to conduct the distance education and eLearning through the state facility, the population of the study at decision maker level is small. To associate with this small population in decision making policy development FAHP seems worthy to us. It seems that the factors along with the membership value will help to understand the situation more appropriately than the AHP method which is used by Bhuasiri et al. In a nutshell, the surrounding environment induces us to use the approach of FAHP to conduct the study.

\subsection{Fuzzy Set}

A fuzzy set A in $\mathrm{X}$ is assumed and defined as a set of ordered pairs

$$
A=\left\{x, \mu_{A}(x) \mid x \in X\right\}
$$

Where $\mathrm{X}$ is the universe of discourse and its elements are denoted by $\mathrm{x}$

\subsection{Factor Selection for the Measurement}

Factors and sub-factors are presented in Figure 1. There are two levels. The first hierarchy factor is $F=\left\{F_{i}\right\}$, ( $i=1,2, \ldots \ldots \ldots m)$ which comes from the second hierarchy factor and $\left\{F_{i j}\right\}(j=1,2, \ldots \ldots n)$

\subsection{Evaluation Index ( $V$ ) for the Selected Factors}

To define the critical success factors of eLearning four different stages are used in the evaluation scale. They are labeled as highly responsible $\left(V_{1}\right)$, highly responsible $\left(V_{2}\right)$, medium responsible $\left(V_{3}\right)$ and normal responsible $\left(V_{4}\right)$ for the successful implementation of eLearning.

\subsection{Weight $(A)$ Assessment for the Selected Factors}

A decision matrix is formulated to assess the weight of selected factors. Ratio scale $1-9$ is used for decision matrix. Decision matrix is denoted by $D$ and is formulated on the basis of the opinion of several academic experts. Procedures and rules of Fuzzy Analytic Hierarchy Process (FAHP) are strictly maintained. Consistency Index (CI) and consequently Consistency Ratio (CR) are calculated on the basis of Largest Eigenvalue $\left(\lambda_{\max }\right)$ and are checked to ensure the validity and reliability of the result.

\subsection{Factor Evaluation Matrix $\left(R_{i}\right)$}

Opinion of teachers and the administrative staffs has been collected to conduct the study. With the opinion of the respondents an evaluation matrix $\left(R_{i}\right)$ is formulated where $r_{i j k}$ is used as a membership grade to indicate the degree of evaluation grade. Opinion of the evaluator's $F_{i j}$ belongs to $V_{k}=(k=1,2,3,4)$. The number of basic factors are denoted by $R_{i}=(i=1,2,3 \ldots \ldots \ldots n)$ indicates the number of basic factors. Evaluation factors are indicated by $1,2, \ldots \ldots . m$ i.e., evaluation sets $V$.

$$
R_{i}=\left\{\begin{array}{cccc}
r_{i 11} & r_{i 12} & \ldots & r_{i 1 m} \\
r_{i 21} & r_{i 22} & \ldots & r_{i 2 m} \\
\ldots & \ldots & \ldots & \ldots \\
r_{i n 1} & r_{i n 2} & \ldots & r_{i n m}
\end{array}\right\}(i=1,2,3,4)
$$

\subsection{Fuzzy Comprehensive Evaluation}

Fuzzy comprehensive evaluation method is started from the lower level to the higher level in a multi-hierarchy evaluation problem i.e., in this study sub-factors to factors. Fuzzy evaluation set in the second hierarchy can be defined as:

$$
B_{i}=A_{i} * R_{i}=\left(b_{i 1}, b_{i 2}, b_{i 3}, b_{i 4}\right) .
$$

In which

$$
b_{i k}=\bigvee_{i=1}^{n}\left(a_{i j} \wedge r_{i j k}\right) \quad(i=1,2,3,4 ; k=1,2,3,4) .
$$

$B_{1}$ has been used to indicate the membership grade of evaluation object $F_{i}$ to evaluation element $V_{k}$ with comprehensive evaluation to each factor $F_{i j}$. Second level of hierarchy is analyzed first, then first level of fuzzy evaluation is introduced.

$$
\tilde{R}=\left\{\begin{array}{l}
B_{1} \\
B_{2} \\
B_{3} \\
B_{4}
\end{array}\right\}=\left\{\begin{array}{l}
A_{1} * \tilde{R}_{1} \\
A_{2} * \tilde{R}_{2} \\
A_{3} * \tilde{R}_{3} \\
A_{4} * \tilde{R}_{4}
\end{array}\right\}=\left[R_{i j}\right]_{4 * 4} .
$$

Fuzzy comprehensive evaluation of second hierarchy; $B=A * R=\left(b_{1}, b_{2}, b_{3}, b_{4}\right)$.

In which

$$
b_{k}=\bigwedge_{i=1}^{n}\left(a_{i j} \wedge r_{i j k}\right) \quad(k=1,2,3,4) .
$$

\subsection{Handling the Evaluation Results}

To handle the fuzzy evaluation, grade weighted vector is used that comes through the AHP approach. The used grade weighted vector is $\mu_{v}=(1,0.75,0.50,0.25)$. The comprehensive value can be divided into several intervals as $[1,0.75],[0.75,0.50],[0.50,0.25],[0.25,0]$ to define the acuteness in CSFs which is labeled as very highly responsible, highly responsible, medium responsible and normal responsible respectively. The parameter is a product of weighted vector $\mu_{v}$ and $B_{k}$.

$$
N=\mu_{v} * B_{k}^{T}=\mu_{v} *\left(b_{1}, b_{2} \ldots \ldots \ldots \ldots \ldots b_{k}\right)^{T} .
$$




\section{Distance Education and eLearning in Bangladesh}

As it has been mentioned earlier, Bangladesh Open University (BOU) is solely authorized in Bangladesh to conduct the distance education. BOU has taken the eLearning as the central platform for distance education to overcome the barriers of time, place and others. BOU is currently using the various state facilities like Bangladesh Television, Bangladesh Radio and others to distribute the knowledge. Activities of BOU is visible in social networks like facebook and in video broadcasting platforms like Youtube. Its self-developed infrastructure e.g., BOUTube and mobile apps are used to conduct the distance education which is known as a mechanism of eLearning. By all these mechanisms BOU is serving a large community in Bangladesh. Its current students are $5,40,733$ (Record of $31^{\text {st }}$ December, 2017) who are admitted through 6 academic schools from 11 administrative divisions. Currently, BOU is running more than 60 academic programs through 12 regional centers and 80 sub-regional centers. It has more than 1502 study centers and 1194 academic centers across Bangladesh.

\subsection{Survey in Bangladesh}

A survey is conducted to the academic and information technology (IT) staff who are involved with the eLearning in BOU. To conduct the survey, a questionnaire was formulated by adopting the model offered by Bhuasiri et al. (2012 (Figure 1)). Data has been collected complying the FAHP. For the basic decision factor, data has been collected from 21 academic and IT staffs. Table 1 presents the data summary for the Infrastructure and System Quality that has been collected in the questionnaire to identify the critical success factors of eLearning in distance education. Data summary of Learners' characteristics, Instructors' characteristics, Institution and service quality, Course and Information quality and Extrinsic motivation are not presented in the paper. Table 1 is presented as an example of basic matrix.

Table 1. Data summary of Infrastructure and system quality

\begin{tabular}{|c|l|c|c|c|c|}
\hline Grade & $\begin{array}{c}V_{1} \\
\text { VHR }\end{array}$ & $\begin{array}{c}V_{2} \\
\mathrm{HR}\end{array}$ & $\begin{array}{c}V_{3} \\
\mathrm{MR}\end{array}$ & $\begin{array}{c}V_{4} \\
\mathrm{NR}\end{array}$ \\
\hline 1 & Internet access quality & 5 & 7 & 7 & 2 \\
\hline 2 & Reliability & 5 & 9 & 5 & 2 \\
\hline 3 & Ease of use & 5 & 8 & 8 & 0 \\
\hline 4 & System functionality & 6 & 10 & 3 & 2 \\
\hline 5 & System interactivity & 6 & 6 & 8 & 1 \\
\hline 6 & System response & 7 & 6 & 5 & 3 \\
\hline
\end{tabular}

From the basic matrix, the Evaluation Matrix $\left(\widetilde{R_{i}}\right)$ has been formulated. An Evaluation Matrix ( $\left.\widetilde{R_{4}}\right)$ which is formulated from Table 1 is presented below as an example.

$$
\widetilde{R_{4}}=\left[\begin{array}{cccc}
.24 & .33 & .33 & .10 \\
.24 & .43 & .24 & .10 \\
.24 & .38 & .38 & 0 \\
.29 & .48 & .14 & .10 \\
.29 & .29 & .38 & .05 \\
.33 & .29 & .24 & .14
\end{array}\right]
$$

On the basis of experts opinion the weights $\left(A_{i}\right)$ have been determined in terms of $1-9$ ratio scale for decision matrix $\left(D_{i}\right)$. As an example decision $\left(D_{4}\right)$ matrix for infrastructure and systems quality is presented below -

$$
D_{4}=\left[\begin{array}{cccccc}
1 & 3 & 3 & 1 / 3 & 1 / 3 & 1 \\
1 / 3 & 1 & 1 & 1 / 5 & 1 / 5 & 1 / 3 \\
1 / 3 & 1 & 1 & 1 / 5 & 1 / 5 & 1 / 3 \\
3 & 5 & 5 & 1 & 1 & 3 \\
3 & 5 & 5 & 1 & 1 & 3 \\
1 & 3 & 3 & 1 / 3 & 1 / 3 & 1
\end{array}\right] .
$$

After normalization of the weight matrix, the priority vector has been determined which are find out as below -

$$
\begin{aligned}
A_{1} & =\left[\begin{array}{lll}
.1062 & .2605 & .6333
\end{array}\right] \\
A_{2} & =\left[\begin{array}{llllll}
.1951 & .0661 & .0661 & .1951 & .0543 & .4234
\end{array}\right] \\
A_{3} & =\left[\begin{array}{lllll}
.2500 & .7500
\end{array}\right] \\
A_{4} & =\left[\begin{array}{llllll}
.1302 & .0531 & .0531 & .3167 & .3167 & .1302
\end{array}\right] \\
A_{5} & =\left[\begin{array}{llll}
.6333 & .1062 & .2605
\end{array}\right] \\
A_{6} & =\left[\begin{array}{llllll}
.2500 & .7500
\end{array}\right] \\
A & =\left[\begin{array}{llllll}
.1284 & .0343 & .0970 & .4076 & .1664 & .1664
\end{array}\right] .
\end{aligned}
$$

The consistency ratios are calculated systematically which are $0.03,0.02,0, .01,0.03,0$ and 0.05 . The ratios are lower than 0.10 (C. $R<0.1$ ). Therefore, the consistency is acceptable. The result of the fuzzy evaluation (equation 5) are given below -

$$
\begin{aligned}
\tilde{B}_{i}=A_{i} * \tilde{R}_{i}=\bigvee_{i=1}^{7}\left(a_{1} \wedge r_{i j}\right) \\
\tilde{B}_{1}=\left(\begin{array}{llll}
.1104 & .3364 & .3949 & .1583
\end{array}\right) \\
\tilde{B}_{2}=\left(\begin{array}{llll}
.1126 & .2335 & .4034 & .2542
\end{array}\right) \\
\tilde{B}_{3}=\left(\begin{array}{llll}
.1000 & .3800 & .3925 & .1300
\end{array}\right) \\
\tilde{B}_{4}=\left(\begin{array}{llll}
.2834 & .3676 & .2718 & .0841
\end{array}\right) \\
\tilde{B}_{5}=\left(\begin{array}{llll}
.1900 & .4114 & .3435 & .0577
\end{array}\right) \\
\tilde{B}_{6}=\left(\begin{array}{llll}
.1000 & .3675 & .4425 & .1000
\end{array}\right) .
\end{aligned}
$$

And

$$
\begin{aligned}
\tilde{B} & =A *\left[\begin{array}{llllll}
\tilde{B}_{1} & \tilde{B}_{2} & \tilde{B}_{3} & \tilde{B}_{4} & \tilde{B}_{5} & \tilde{B}_{6}
\end{array}\right]^{T} \\
& =\left(\begin{array}{llll}
.1900 & .3690 & .3415 & .1010
\end{array}\right) .
\end{aligned}
$$

Fuzzy evaluation is corresponded with all the respective sub-factors systematically.

\section{Results/Defuzzification}

Parametric representation method is used for the determination of fuzzy comprehensive value. The values are given below -

$$
\begin{aligned}
N_{1}= & \mu * \tilde{B}_{1}^{T}=(1, .75, .50, .25) \\
& *(.1104, .3364, .3949, .1583)^{T} \\
& =.60 \\
N_{2}= & \mu * \tilde{B}_{2}^{T}=(1, .75, .50, .25) \\
& *(.1126, .2335, .4034, .2542)^{T} \\
& =.55
\end{aligned}
$$




\begin{tabular}{|c|c|}
\hline 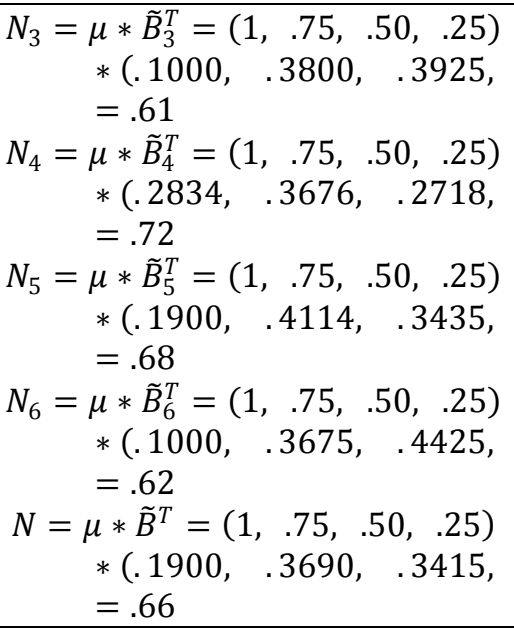 & $.0577)^{T}$ \\
\hline
\end{tabular}

The defuzzification shows the single value for the factors regarding the critical success factors (CFS) of adopting eLearning in the distance education systems in Bangladesh. As per the defuzzification, Infrastructure and system quality is the most critical success factors for eLearning. Course and information quality, Extrinsic Motivation, Institution and service quality, Learners' characteristics and Instructors' characteristics are in second, third, fourth and in fifth position respectively.

\section{Conclusions}

Through the exploration of scenario by FAHP in adopting eLearning in Bangladesh the study contributes to the eLearning adoption scenario in developing countries endeavor. In previous studies both the developed and developing countries are investigated in these regards. In developing countries it is found that developing countries are suffering from the problem of infrastructure and good systems very often [14]. The findings of our study are identical with previous studies. The defuzzification shows that in Bangladesh Infrastructure and system quality is seemed as the most critical success factor (CSF) for successful implementation of eLearning in the distance education program. The infrastructure and system quality includes internet access quality, reliability, ease of use, system functionality, system interactivity and system response. Therefore the infrastructure and system quality including the sub-factors are suggested to be taken care of. However, it should be mentioned that only the revision of the noticed factor is not the solution to ensure the efficiency. The revision should be harmonized with the other factors as the factors are interlined or might be interlinked. For example; an excellent infrastructure and system will be useless without the skilled academic and administrative staffs. In general, the study tries to make the sense from which point reformation should be started to ensure the effective and efficient eLearning in the distance education to reach the targeted people and distribute the knowledge to them. Therefore, by identifying the rounds of revision and showing the possible extension of study, this paper reveals some scope for future research.

\section{Acknowledgements}

The paper is developed at the time of working in the project "Gender Perception in Distance Learning of Bangladesh Open University" supported by Bangladesh Open University (BOU).

\section{References}

[1] Spector, J. M., Merrill, M. D., Elen, J., and Bishop, M. J. (Eds.). Handbook of research on educational communications and technology. $3^{\text {rd }}$ Edition, New York, NY: Routledge, 2008.

[2] Abrami, P. C., and Bures, E. M. "Computer-supported collaborative learning and distance education,” American Journal of Distance Education, 10(2). 37-42. 1996.

[3] Bates, A. W. Technology, e-Learning and Distance Education, 2nd ed. New York: Routledge, 2005.

[4] Islam, M. T., and Selim, A. S. M. "Information and communication technologies for the promotion of open and distance learning in Bangladesh. Journal of Agriculture and Rural Development," 4(1). 35-42. 2006.

[5] Shohel, M. M. C., and Power, T. "Introducing mobile technology for enhancing teaching and learning in Bangladesh: teacher perspectives," Open Learning: The Journal of Open, Distance and e Learning, 25(3). 201 - 215. 2010.

[6] Bhuasiri, W., Xaymoungkhoun, O., Zo, H., Rho, J. J., and Ciganek, A. P. "Critical success factors for e-learning in developing countries: A comparative analysis between ICT experts and faculty," Computers \& Education, 58(2). 843-855. 2012.

[7] Moore, J. L., Dickson-Deane, C., and Galyen, K. "e-Learning, online learning, and distance learning environments: Are they the same?,” The Internet and Higher Education, 14(2). 129-135. 2011.

[8] Dede, C. "The evolution of distance education: Emerging technologies and distributed learning," American Journal of Distance Education, 10(2). 4-36. 1996

[9] Clark, R. "Six principles of effective e-Learning: What works and why,” The e-Learning Developer's Journal, 6(2). 1-10. 2002.

[10] McPherson, M., and Baptista Nunes, M. "Organisational issues for e-learning: Critical success factors as identified by $\mathrm{HE}$ practitioners," International Journal of Educational Management, 20(7). 542-558. 2006.

[11] Selim, H. M. (2007). Critical success factors for e-learning acceptance: Confirmatory factor models. Computers \& Education, 49(2), 396-413

[12] Sun, P. C., Tsai, R. J., Finger, G., Chen, Y. Y., and Yeh, D. "What drives a successful e-Learning? An empirical investigation of the critical factors influencing learner satisfaction." Computers \& education, 50(4). 1183-1202. 2008

[13] Sridharan, B., Deng, H., and Corbitt, B. "Critical success factors in e-learning ecosystems: a qualitative study," Journal of Systems and Information Technology, 12(4). 263-288. 2010.

[14] Andersson, A., and Grönlund, A. "A conceptual framework for e-learning in developing countries: A critical review of research challenges," The electronic Journal of information systems in developing Countries, 38(1). 1-16. 2009.

[15] Perraton, H. Open and distance learning in the developing world. Routledge, 2012

[16] Tarhini, A., Hone, K., and Liu, X. "The effects of individual differences on e-learning users' behaviour in developing countries: A structural equation model," Computers in Human Behavior, 41. 153-163. 2014

[17] Rajib, M., and Fan, L. "A study on the critical factors of human error in civil aviation: An early warning management perspective in Bangladesh,” Management Science Letters, 5(1), 21-28. 2015. 